View Article Online / Journal Homepage / Table of Contents for this issue

THE SOLUBILITY OF TRIPHENYLMETHANE.

1013

\title{
CV.-The Solubility of Triphenylmethane in Organic Liquids with which it forms Crystalline Compounds.
}

By Harold Hartley, M.A., Fellow of Balliol College, and Noel Garrod Thomas, Brakenbury Scholar, Balliol College.

KekUle and Franchimont (Ber., 1872, 5, 967), when they first prepared triphenylmethane, noticed that it crystallised from benzene with one molecule of benzene of crystallisation, and Anschütz (Annalen, 1886, 235, 208) found that the compound lost 24.22 per cent. of its weight when heated to $100^{\circ}$, the theoretical loss for a substance of formula $\mathrm{CH}(\mathrm{Ph})_{3} \cdot \mathrm{C}_{6} \mathrm{H}_{6}$ being $25 \cdot 36$ per cent.

Liebermann (Ber., 1893, 26, 853) crystallised triphenylmethane from thiophen and obtained crystals with thiophen of crystallisation, which was rapidly lost on standing. The crystals lost 24.54 per cent. of their weight when heated to $100^{\circ}$, the theoretical loss for $\mathrm{CH}(\mathrm{Ph})_{3} \cdot \mathrm{C}_{4} \mathrm{H}_{4} \mathrm{~S}$ being $25 \cdot 61$ per cent.

Lehmann (Zeit. Kryst. Min., 1881, 5, 472), who studied the crystallisation of triphenylmethane from aniline microscopically, stated that it crystallised in two forms belonging to the rhombohedral and monoclinic systems, which differ in the amount of aniline of crystallisation, but he made no attempt to estimate this amount in either case. Hintze (Zeit. Kryst. Min., 1884, 9, 545) made some measurements on "weathered" crystals from benzene solution and pointed out that if the crystals containing aniline resembled those containing benzene, I,ehmann's two forms were probably identical, their difference in 
appearance under the microscope being due to a different development of the basal plane.

Linebarger (Amer. Chem. J., 1893, 15, 45) was the first to study the solubility of triphenylmethane in benzene, his determinations being made by the ordinary method. As, however, he heated the triphenylmethane to $200^{\circ}$ to get rid of the last traces of benzene, and at this temperature the substance itself is appreciably volatile, his results were necessarily inaccurate; they differ from the later determinations of Kuriloff (Zeit. physikal. Chem., 1897, 23, 547), which agree closely with those found by the authors, using a slightly modified form of his method.

The first object of the present work was to determine if there were any other solvents which form crystalline compounds with triphenylmethane; only pyrrole was found to do so. Solutions in mesitylene, $o-, m$-, and $p$-xylene, toluene, pyridine, piperidine, nitrobenzene, chlorotoluene, benzyl alcohol, quinoline, bromobenzene, chlorobenzeve, methylbenzoate, phenyl acetate, propyl alcohol, acetone, chloroform, ethylene dibromide, alcohol, and ether all gave orthorhombic crystals of pure triphenylmethane.

A microscopic study has been made of the crystals containing benzene, thiophen, pyrrole, and aniline of crystallisation, all of which decompose rapidly on being removed from the solution in which they have grown, the faces becoming dull and giving very poor reflections on the goniometer. We hope soon to measure them while growing in a solution by means of Prof. Miers' inverted goniometer.

The solubility of triphenylmethane in the four liquids above mentioned has been determined, and, for purposes of comparison with a case in which no compound with the solvent existed, a set of determinations was also made in pyridine.

Besides the solubility determinations, a series of observations was made at the suggestion of Prof. Miers to see at what degree of supersaturation solutions of triphenylmethane would crystallise spontaneously, after they had been completely freed from crystal nuclei. This was done by heating them considerably above the temperature at which all the solid in contact with the solution had dissolved, and then cooling until the crystallisation occurred. Spontaneous crystallisation in such a case has been found to occur at a definite temperature, thus fixing the limit of the "metastable state" in which, although supersaturated, a solution cannot crystallise without the addition of a crystal particle (Ostwald, Lehrbuch der Allgemeinen Chemie, 2, 773). 


\section{Experimentat.}

\section{Preparation of Materials.}

The triphenylmethane used was prepared by the ordinary method from Kahlbaum's chloroform and benzene with freshly made aluminium chloride. It was recrystallised twice from benzene and at least twelve times from alcohol until it gave a constant m. p. of $93.2^{\circ}$ (corr.); this is slightly higher than the number given by Kuriloff $\left(92^{\circ}\right)$. The solvents used were all obtained from Kahlbaum or Merck, and carefully redistilled just before use.

\section{Method of Determining the Solubility.}

The ordinary methods for determining solubilities being difficult to use owing (1) to the volatility of benzene, thiophen, and pyrrole; (2) to the difficulty of estimating the relative amounts of aniline and triphenylmethane in a mixture of the two, and (3) to the small amounts of substance available, we resorted to a modification of the method used by Kuriloff (loc. cit.).

The latter heated sealed tubes containing known quantities of triphenylmethane and benzene in a water-bath with constant shaking until the last crystals just dissolved. In this way the temperature of saturation was found for solutions of known composition. It is rather hard to say when the last crystals disappear, as they dissolve very slowly in a solution which is nearly saturated. When, on the other hand, we contrived by successive cooling and warming that there should be in the tube only one or two small crystals at a temperature near that of saturation, it was easy, by watching the small crystals with a lens while the temperature of the bath was raried, to find two temperatures differing by $0.4^{\circ}$ to $0.5^{\circ}$, at the lower of which the crystals were growing with sharp edges, whilst at the higher temperature the rounded edges and faces showed that they were dissolving. The mean of these two temperatures may be taken as the temperature of saturation without introducing a large error. The results obtained in successive determinations are quite concordant and the method has several advantages, as it is quick, requires very little substance, and may be used for any volatile solvent; the fact that it necessitates the close study of the crystals with which the solution is in equilibrium leaves no ambiguity as to their nature. The most useful form of tube was made by blowing a bulb at one end of a short piece of quill tubing and making a small constriction in the middle. After careful drying the tube is weighed, some of the solid is introduced, and it is weighed again; then the required quantity of liquid is added from a small pipette, and, after a third 
weighing, the tube is sealed at the constriction. The open end is closed by a small cap during the weighing and sealing to avoid loss by evaporation, and contact with the hand is carefully avoided for the same reason. The tubes were heated in a large beaker of water, jacketed with felt, and stirred by means of a hot air engine. By adjusting the size of the Bunsen flame, the temperature of the water could be kept constant for as long as was necessary.

In order to determine the temperature of spontaneous crystallisation, the tube is heated in a large beaker of water at $10^{\circ}$ above the saturation temperature to destroy all traces of crystal nuclei, and it is then allowed to cool slowly with constant shaking until crystals appear.

The spontaneous production of crystals never occurs until a temperature is reached at which the solution is considerably supersaturated, and then many small crystals suddenly make their appearance. At least two determinations were made with each tube; as a rule they agreed within $1^{\circ}$, which was fairly satisfactory considering the nature of the phenomenon, and the extent to which it would be influenced by such factors as the rate of cooling. The time taken for cooling in most of the experiments was between half an hour and an hour. A curve may be plotted from the results showing the concentration at which the spontaneous crystallisation of a solution at any given temperature occurs. In the region between the solubility curve and this second curve, for which Prof. Miers has suggested the name "supersolubility curve," supersaturated solutions can exist without crystallising until a crystal nucleus is introduced.

\section{Triphenylmethans and Benzene.}

The results of the determination of solubility and of the temperature at which spontaneous crystallisation takes place are given in the table on p. 1017, and are shown graphically in Fig. 1 (p. 1018), where the ordinates represent molecular percentages and the abscissæ temperatures.

The solubility curve consists of two parts, of which $A B$ represents the solubility of triphenylmethane in benzene, and $B C D$ the solubility of the compound $\mathrm{CH}(\mathrm{Ph})_{3} \cdot \mathrm{C}_{6} \mathrm{H}_{6}, C$ being its melting point, which is depressed by the addition of benzene or of triphenylmethane. The point in which the two cut $(B)$ is a eutectic point for the compound and pure triphenylmethane. The large curvature of the retroflex portions of the lower curve indicates that the compound is almost entirely dissociated in the solution (Stortenbecker, Zeit. physikal Chem., 1892, 10, 194). It will be seen that the "supersolubility curve" also consists of two parts which run, roughly speaking, parallel to the two 


\section{Solubility of Triphenylmethane in Benzene.}

\begin{tabular}{|c|c|c|c|c|c|c|c|}
\hline $\begin{array}{l}\text { Gram of } \\
\text { triphenyl- } \\
\text { methane. }\end{array}$ & $\begin{array}{c}\text { Gram } \\
\text { of } \\
\text { benzene. }\end{array}$ & $\begin{array}{l}\text { Percent- } \\
\text { age of } \\
\text { triphenyl- } \\
\text { methane. }\end{array}$ & $\begin{array}{l}\text { Molecular } \\
\text { percent- } \\
\text { age of } \\
\text { triphenyl } \\
\text { methane. }\end{array}$ & $\begin{array}{l}\text { S } \\
\text { Saturation } \\
\text { tem- } \\
\text { perature. }\end{array}$ & $\begin{array}{c}\text { Form } \\
\text { of } \\
\text { crystals. }\end{array}$ & $\begin{array}{l}\text { Limit of } \\
\text { metastable } \\
\text { region. }\end{array}$ & $\begin{array}{c}\text { Form } \\
\text { of } \\
\text { crystals. }\end{array}$ \\
\hline 0.5682 & 0.0254 & $95 \cdot 7$ & $87 \cdot 8$ & $86.6^{\circ}$ & $\mathrm{N}$ & $67 \cdot 3^{\circ}, 65 \cdot 5$ & $5^{\circ} \quad \mathrm{N}$ \\
\hline 0.5392 & 0.0400 & $93 \cdot 1$ & $81 \cdot 3$ & $82 \cdot 3$ & $\mathrm{~N}$ & $58 \cdot 5,58 \cdot 4$ & $\mathrm{~N}$ \\
\hline 0.5417 & 0.0568 & 90.5 & $75 \cdot 3$ & $78 \cdot 8$ & $\mathrm{~N}$ & $62 \cdot 6,62 \cdot 4$ & $\mathrm{RN}$ \\
\hline 0.6850 & 0.0846 & $89 \cdot 0$ & $72 \cdot 2$ & $76 \cdot 0$ & $\mathrm{~N}$ & $63 \cdot 8,63 \cdot 8$ & $\mathrm{RN}$ \\
\hline 0.4969 & 0.0714 & $87 \cdot 5$ & $69 \cdot 1$ & $74 \cdot 6$ & $\mathrm{~N}$ & $65 \cdot 4,64 \cdot 5$ & $\mathrm{RN}$ \\
\hline 0.4822 & 0.0911 & $84 \cdot 1$ & $62 \cdot 8$ & $76 \cdot 2$ & $\mathrm{R}$ & $66 \cdot 8,66 \cdot 2$ & $\mathrm{R}$ \\
\hline 0.6157 & 0.1523 & $80 \cdot 2$ & $56 \cdot 4$ & $77 \cdot 5$ & $\mathbf{R}$ & $69 \cdot 2,68 \cdot 7$ & $\mathrm{R}$ \\
\hline 0.3848 & 0.1198 & $76 \cdot 3$ & $50 \cdot \overline{7}$ & $77 \cdot 9$ & $\mathrm{R}$ & $69 \cdot 3,68 \cdot 7$ & $\mathrm{R}$ \\
\hline 0.4222 & 0.2043 & $67 \cdot 4$ & $39 \cdot 7$ & $77 \cdot 1$ & $\mathrm{R}$ & $70 \cdot 3,69 \cdot 8$ & $\mathbf{R}$ \\
\hline 0.2992 & 0.2212 & $57 \cdot 5$ & $30 \cdot 2$ & $73 \cdot 8$ & $\mathrm{R}$ & $67 \cdot 6,67 \cdot 2$ & $R$ \\
\hline 0.2357 & 0.3617 & $38 \cdot 9$ & $17 \cdot 2$ & $65 \cdot 6$ & $\mathrm{R}$ & $58 \cdot 3,58 \cdot 0$ & $\mathrm{R}$ \\
\hline $0 \cdot 1600$ & 0.5064 & $24 \cdot 0$ & $8 \cdot 8$ & $49 \cdot 4$ & $\mathrm{R}$ & $42 \cdot 1,41 \cdot 7$ & $\mathrm{R}$ \\
\hline 0.0636 & 0.4395 & $12 \cdot 6$ & $4 \cdot 4$ & $33 \cdot 0$ & $\mathrm{R}$ & $28 \cdot 0,27 \cdot 5$ & $\mathrm{R}$ \\
\hline
\end{tabular}

$\mathrm{N}$ denotes monoclinic needles $\left(\mathrm{CHPh}_{3}\right)$.

R, rhombs $\left(\mathrm{CHPh}_{3} \cdot \mathrm{C}_{6} \mathrm{H}_{6}\right)$.

parts of the solubility curve. The range of the "metastable region" is about $20^{\circ}$ for solutions which deposit crystals of pure triphenylmethane and about $7^{\circ}$ for those which deposit crystals containing benzene of crystallisation. Thus, for the formation of crystals of the compound, a smaller degree of supersaturation is needed than is the case with the pure substance; in consequence of this, solutions containing from $70-80$ mols. per cent. of triphenylmethane, which are normally in equilibrium with crystals of the pure substance, if freed from crystal nuclei and cooled, deposit crystals of the compound while still within the metastable region of the pure substance. For instance, a solution containing 75 mols. per cent. of triphenylmethane, when cooled to $63^{\circ}$, deposits rhombohedral crystals of the compound, and these have the property of starting the crystallisation of orthorhombic needles of triphenylmethane when placed in solutions which are in the metastable condition as regards the latter substance. The orthorhombic needles grow on the rhombohedra, so that the vertical axes of both are parallel as in Fig. 2. The edges of the needles are usually curved owing to the rapidity of their growth in its initial stages. The second erystallisation takes place very rapidly after the first, and the sequence is sometimes rather hard to observe. It will be seen that in the cases where this occurs (marked RN on the table and indicated on the diagram by $\oplus$ ) the temperatures of crystallisation lie on the continuation of the curve which represents the limit of supersaturation for the compound. 


\section{The Compound of Triphenylmethane and Benzene.}

The composition of this body was shown by Anschütz to be $\mathrm{CH}(\mathrm{Ph})_{3} \cdot \mathrm{C}_{6} \mathrm{H}_{6}$. Hintze measured some of the "weathered" crystals

FIG. 1.--Solubility and supersolubility curves of triphenylmethane in benzene.

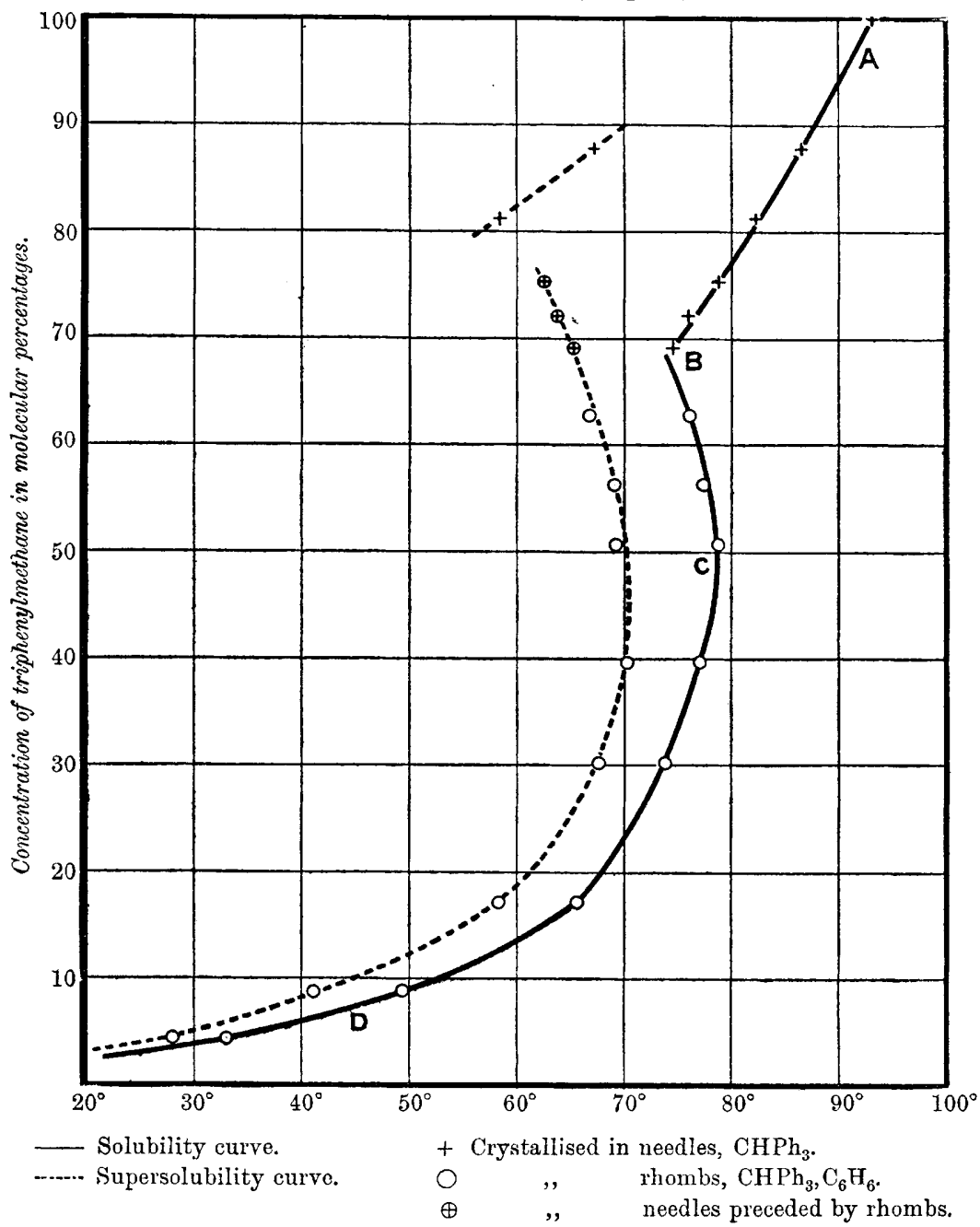

which had lost their benzene of crystallisation and found them to be rhombohedra with a rhombohedral angle $110^{\circ} 13^{\prime}$ and $a: c=1.5565$. We have studied a large number of crystallisations under the micro- 
scope; the most frequent habits of the crystals are (1) a simple rhombohedron, (2) a combination of rhombohedron and small basal plane (Fig. 3), (3) a combination of rhombohedron and basal plane equally developed (Fig. 4), and (4) the same combination with the basal plane predominating (Fig. 5).

The crystals have a high refractive index and are strongly birefringent. Viewed in convergent light in a direction perpendicular to the basal plane, they show a uniaxial interference figure of negative character, which confirms the other evidence as to their symmetry. No distinct etching figures could be obtained on the rhombohedron faces,

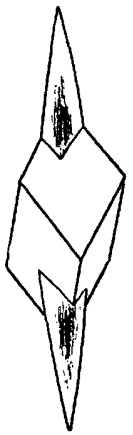

FIG. 2.

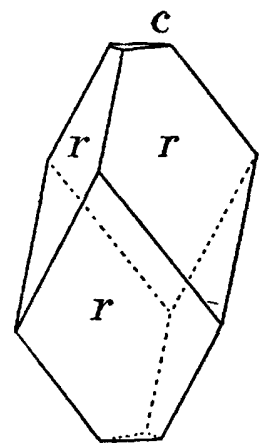

FIG. 3.

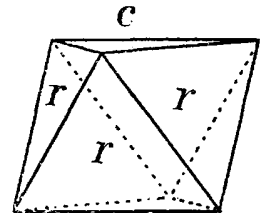

FIG. 4.

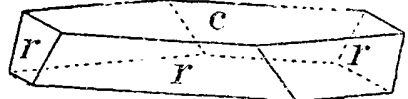

FIG. 5 .

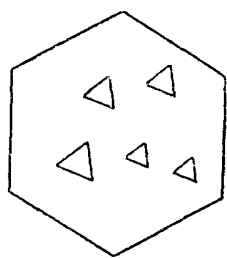

FIG. 6.

but in the initial stage of solution the basal plane was pitted by small triangular depressions arranged unsymmetrically with respect to its edges as shown in Fig. 6. The crystals thus posiess an axis of threefold symmetry, but no plane of symmetry. There is no evidence of hemimorphism, as both ends of the crystals are equally developed, and behave in the same way in starting the crystallisation of orthorhombic needles of triphenylmethane as mentioned above. The latter crystals are hemimorphic, and the two ends grow at very different speeds, but when their crystallisation is started by a rhombohedral crystal of the compound, they grow outwards from both apices of the rhombohedron with faster-growing ends directed outwards from the 
crystal in each case, showing that there is no difference between the faces $(111)$ and $(\overline{1} \overline{1} \overline{1})$.

The crystals of the compound thus possess an axis of threefold symmetry and a centre of symmetry, and belong to the dioptase class.

A number of measurements of the angle between the two edges of a rhombohedron face showed that this is approximately $60^{\circ}$; the rhombohedron angle (100): (010) calculated from this value is $109^{\circ} 28^{\prime}$, which differs slightly from Hintze's measurement on a "weathered" crystal $\left(110^{\circ} 13^{\prime}\right)$. In a rhombohedral crystal with the angle $(100):(010)=109^{\circ} 28^{\prime}$, both the angles $(100):(111)$ and $(100):(010)$ have the value $70^{\circ} 32^{\prime}$ (the octahedron angle), so that a crystal with the forms $\{111\}$ and $\{100\}$ equally developed is indistinguishable geometrically from a regular octahedron.

The effect of this curious symmetry of angle is seen in the present case in the form of the interpenetrant twins and triplets which frequently occur. The crystals twin about an axis which is parallel to a rhombohedron edge, giving rise to interpenetrant twins of the form seen in Fig. 7, where the shading indicates the relative positions of the two individuals and the extent to which they overlap. The letters $r^{\prime} c^{\prime}, r^{\prime \prime} e^{\prime \prime}$ show which faces belong to each individual. The extinction directions of the two parts of the twin make an angle of $60^{\circ}$ with one another, and, as would be expected, no re-entrant angle is visible under the microscope where the faces of the two individuals meet.

Still more frequent is the formation of triplets where the three individuals interpenetrate regularly, as in Fig. 8; sometimes the basal planes $\{111\}$ are developed sufficiently to give rise to the form shown in Fig. 9. In this case the crystal appears at first sight to be a simple combination of the forms $\{111\}$ and $\{100\}$, as in Fig. 5, but optical examination shows that the apparent basal plane is composed of the rhombohedral faces of three individuals, as is evident from the interference figures seen through the six sections of the face, which are shown in Fig. 9. The six small faces bounding the hexagonal plane are the basal planes of the three individuals. Here, again, the regular formation without visible re-entrant angles shows that the rhombohedron angle of the single crystals must be approximately $109^{\circ} 28^{\prime}$. Figs. 7, 8, and 9 are plans representing the crystals just as they are seen through a microscope.

When simple crystals of the type represented in Fig. 5 start to grow in strongly supersaturated solutions, they give rise to skeletal forms in accordance with Lehmann's theory that the latter are due to a difference in the rate of supply of material for crystallisation at different points of a growing crystal. Suppose that a crystal is growing with its basal plane resting on the microscope slide, it grows 
laterally by the deposition of substance on the six rhombohedron faces. Now, of the six rhombohedron faces, three have the edge which extends furthest into the solution practically in contact with the glass, and three have the corresponding edge in the middle of the drop of solution. The latter must therefore receive a more rapid supply of the excess of dissolved substance, and will grow faster, and these three faces, having once pushed themselves further into the solution

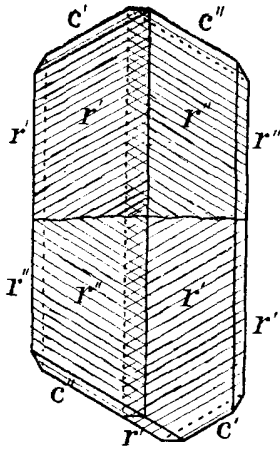

Fig. 7 .

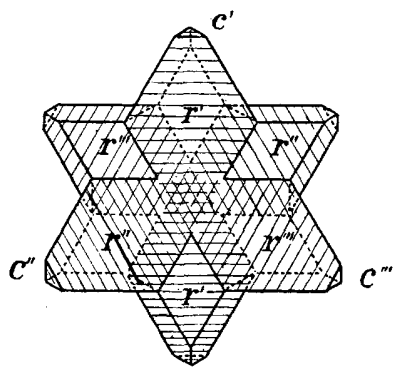

Frg. 8.

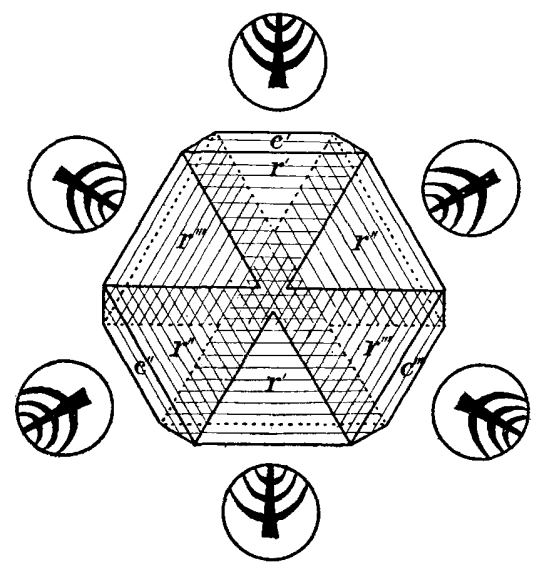

Frg. 9.

than the rest, will intercept much of the material which would otherwise go towards increasing the remaining faces. The three arms which are terminated by the faces $(\overline{1} 00),(0 \overline{1} 0)$, and $(00 \overline{1})$ grow outwards until the excess of supersaturation is removed, and then the crystal adjusts itself to the condition of normal equilibrium between a crystal and its solution, so that finally the gaps are filled up and a regular crystal is formed. 


\section{Triphenylmethane and Thiophen.}

The determinations were exactly the same as for benzene, and the results are given in the following table and figure:

Solubility of Triphenylmethane in Thiophen.

\begin{tabular}{|c|c|c|c|c|c|c|c|}
\hline $\begin{array}{l}\text { Gram of } \\
\text { triphenyl- } \\
\text { methane. }\end{array}$ & $\begin{array}{c}\text { Gram } \\
\text { of } \\
\text { thiophen. }\end{array}$ & $\begin{array}{l}\text { Percent- } \\
\text { age of } \\
\text { triphenyl- } \\
\text { methane. }\end{array}$ & $\begin{array}{l}\text { Molecular } \\
\text { percent- } \\
\text { age of } \\
\text { triphenyl- } \\
\text { methane. }\end{array}$ & $\begin{array}{l}\text { Saturation } \\
\text { tem- } \\
\text { perature. }\end{array}$ & $\begin{array}{c}\text { Form } \\
\text { of } \\
\text { crystals. }\end{array}$ & $\begin{array}{l}\text { Limit of } \\
\text { metastable } \\
\text { region. }\end{array}$ & $\begin{array}{c}\text { Form } \\
\text { of } \\
\text { crystals }\end{array}$ \\
\hline 0.5223 & 0.0205 & $96 \cdot 2$ & $89 \cdot 9$ & $87.2^{\circ}$ & $\mathrm{N}$ & - & - \\
\hline 0.4410 & 0.0472 & $90 \cdot 3$ & $76 \cdot 3$ & $79 \cdot 0$ & $\mathrm{~N}$ & - & - \\
\hline 0.7208 & $0 \cdot 1038$ & $87 \cdot 4$ & $70 \cdot 5$ & $74 \cdot 2$ & $\mathrm{~N}$ & $53 \cdot 1^{\circ}, 52 \cdot 6^{\circ}$ & $\mathrm{N}$ \\
\hline 0.5260 & 0.1145 & $82 \cdot 1$ & $61 \cdot 3$ & $67 \cdot 2$ & $\mathrm{~N}$ & $49 \cdot 4,49 \cdot 4$ & $\mathrm{RN}$ \\
\hline 0.4553 & 0.1008 & $81 \cdot 9$ & $60 \cdot 8$ & $67 \cdot 0$ & $\mathrm{~N}$ & $50.0,496$ & $R N$ \\
\hline 0.3725 & 0.1008 & $78 \cdot 7$ & $56 \cdot 0$ & $62 \cdot 7$ & $\mathrm{~N}$ & $51 \cdot 0,51 \cdot 0$ & $\mathrm{RN}$ \\
\hline 0.3827 & $0 \cdot 1288$ & $74 \cdot 8$ & $50 \cdot 6$ & $57 \cdot 6$ & $\mathrm{R}$ & $51 \cdot 5,51 \cdot 2$ & $\mathrm{R}$ \\
\hline 0.4014 & 0.1701 & $70 \cdot 2$ & $44 \cdot 7$ & $57 \cdot 4$ & $\mathrm{R}$ & $51 \cdot 6,51 \cdot 3$ & $\mathrm{R}$ \\
\hline 0.6469 & 0.4539 & $58 \cdot 7$ & $32 \cdot 9$ & $53 \cdot 5$ & $\mathrm{R}$ & $47 \cdot 5,47 \cdot 5$ & $\mathrm{R}$ \\
\hline 0.4771 & 0.5087 & $48 \cdot 4$ & $24 \cdot 4$ & $47 \cdot 6$ & $\mathrm{R}$ & $40 \cdot 7,40 \cdot 3$ & $\mathrm{R}$ \\
\hline 0.1148 & $0 \cdot 1482$ & $43 \cdot 6$ & $21 \cdot 1$ & $44^{\circ} 0$ & $\mathrm{R}$ & - & - \\
\hline 0.3353 & 0.7411 & $31 \cdot 1$ & $13 \cdot 5$ & $33 \cdot 5$ & $\mathrm{R}$ & $25 \cdot 5,25 \cdot 4$ & $\mathrm{R}$ \\
\hline 0.2733 & 0.7768 & $26 \cdot 0$ & $10 \cdot 8$ & $25 \cdot 7$ & $\mathrm{R}$ & 1 & - \\
\hline
\end{tabular}

$\mathrm{N}$ denotes monoclinic needles $\left(\mathrm{CHPh}_{3}\right)$.

$\mathrm{R}$ " rhombs $\left(\mathrm{CHPh}_{3} \cdot \mathrm{C}_{4} \mathrm{H}_{4} \mathrm{~S}\right)$.

The curves in this case are of much the same form as with benzene, except that the solubility curve for the pure substance cuts the curve for the compound much nearer to the melting point, the thiophen compound thus having a smaller range of existence than that with benzene. The range of the "metastable region" is almost the same as in the case of benzene solutions.

\section{The Compound of Triphenylmethane and Thiophen.}

Liebermann's analysis showed that it had the composition

$$
\mathrm{CHPh}_{3} \cdot \mathrm{C}_{4} \mathrm{H}_{4} \mathrm{~S} \text {; }
$$

in crystalline form, it is exactly analogous to the benzene compound, its crystals appearing under the microscope of exactly the same form and habit, with the same twin law and similar optical properties, so that so far as microscopic evidence is of value they seem to be isomorphous. The crystals decomposed too rapidly to admit of goniometric measurement. The formation of hexagonal-shaped triplets in 
which no re-entrant angles are visible shows that, as is the case with benzene, the angle between the rhombohedral edges must be approximately $60^{\circ}$, and the rhombohedron angle $109^{\circ} 28^{\prime}$.

FIG. 10. - Solubility and supersolubility curves of triphenylmethane in thiophen.

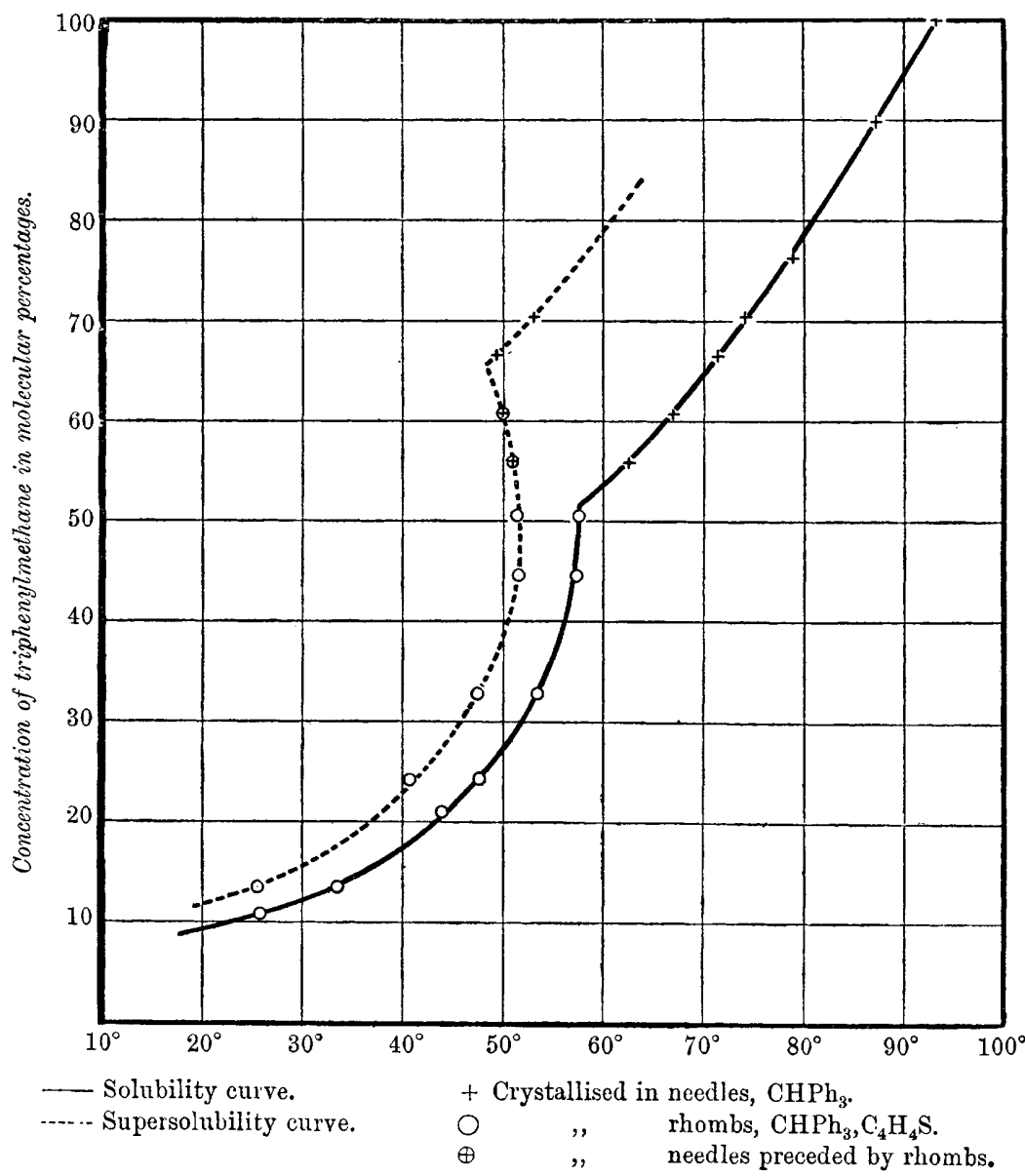

Triphenylmethane and Pyrrole.

The results of the solubility and supersolubility determinations are given in the following table and figure: 
Solubility of Triphenylmethane in Pyrrole.

\begin{tabular}{|c|c|c|c|c|c|c|c|}
\hline $\begin{array}{l}\text { Gram of } \\
\text { triphenyl- } \\
\text { methane. }\end{array}$ & $\begin{array}{c}\text { Gram } \\
\text { of } \\
\text { pyrrole. }\end{array}$ & $\begin{array}{l}\text { Percent- } \\
\text { age of } \\
\text { triphenyl- } \\
\text { methane. }\end{array}$ & $\begin{array}{l}\text { Molecular } \\
\text { percent- } \\
\text { age of } \\
\text { triphenyl- } \\
\text { methane. }\end{array}$ & $\begin{array}{l}\text { Saturation } \\
\text { tem- } \\
\text { perature. }\end{array}$ & $\begin{array}{c}\text { Form } \\
\text { of } \\
\text { crystals. }\end{array}$ & $\begin{array}{l}\text { Limit of } \\
\text { metastable } \\
\text { region. }\end{array}$ & $\begin{array}{c}\text { Form } \\
\text { of } \\
\text { crystals. }\end{array}$ \\
\hline 0.6765 & 0.0166 & $97 \cdot 6$ & $91 \cdot 8$ & $89 \cdot 2^{\circ}$ & $\mathrm{N}$ & $69 \cdot 7^{\circ}, 66 \cdot 2^{\circ}$ & $\circ \quad \mathrm{N}$ \\
\hline 0.7583 & 0.0337 & $95 \cdot 7$ & $86 \cdot 1$ & $86 \cdot 2$ & $\mathrm{~N}$ & $64 \cdot 6,64 \cdot 1$ & $\mathrm{~N}$ \\
\hline $0 \cdot 7528$ & 0.0698 & $91 \cdot 5$ & $74 \cdot 8$ & $80 \cdot 1$ & $\mathrm{~N}$ & $59 \cdot 0,56 \cdot 9$ & $\mathrm{~N}$ \\
\hline 0.4802 & 0.0887 & $84 \cdot 4$ & $59: 8$ & $71 \cdot 1$ & $\mathrm{~N}$ & $51 \cdot 2,50 \cdot 2$ & $\mathrm{~N}$ \\
\hline 0.5041 & $0 \cdot 1116$ & $81 \cdot 9$ & $55 \cdot 6$ & $68 \cdot 5$ & $\mathrm{~N}$ & $47 \cdot 5,42 \cdot 5$ & $\mathrm{~N}$ \\
\hline 0.7695 & 0.2040 & $79 \cdot 0$ & $50 \cdot 9$ & $65 \cdot 6$ & $\mathrm{~N}$ & $41.5,40.2$ & $\mathrm{~N}$ \\
\hline 0.5570 & 0.1696 & $76 \cdot 7$ & $47 \cdot 4$ & $63 \cdot 9$ & $\mathrm{~N}$ & $38 \cdot 0,36 \cdot 5$ & $\mathrm{~N}$ \\
\hline 0.6087 & 0.2279 & $72 \cdot 8$ & $42 \cdot 3$ & $60 \cdot 8$ & $\mathrm{~N}$ & $35 \cdot 6,35 \cdot 4$ & $\mathrm{~N}$ \\
\hline 0.4158 & 0.1592 & $72 \cdot 3$ & $41 \cdot 8$ & $60 \cdot 0$ & $\mathrm{~N}$ & $36 \cdot 1,35 \cdot 4$ & $N$ \\
\hline 0.6013 & 0.3391 & 63.9 & $32 \cdot 8$ & $53 \cdot 2$ & $\mathrm{~N}$ & $35 \cdot 3,31 \cdot 2$ & $\mathrm{RN}$ \\
\hline 0.4487 & 0.3520 & $56 \cdot 0$ & $25 \cdot 9$ & $46 \cdot 9$ & $\mathrm{~N}$ & $34 \cdot 4,34 \cdot 3$ & $\mathrm{RN}$ \\
\hline $0 \cdot 3318$ & 0.3442 & $49 \cdot 1$ & $20 \cdot 9$ & $42 \cdot 7$ & $N$ & $29 \cdot 8,29 \cdot 7$ & RN \\
\hline 0.3552 & 0.5192 & $40 \cdot 6$ & $15 \cdot 8$ & $36 \cdot 8$ & $\mathrm{~N}$ & - & $\ldots$ \\
\hline 0.2021 & 0.4025 & $33 \cdot 4$ & $12 \cdot 1$ & $31 \cdot 5$ & $\mathbf{R}$ & - & - \\
\hline 0.2367 & 0.5585 & $29 \cdot 8$ & $10 \cdot 4$ & $29 \cdot 0$ & $\mathrm{R}$ & - & - \\
\hline $0 \cdot 2272$ & $0 \cdot 7062$ & $24 \cdot 3$ & $8 \cdot 1$ & $24 \cdot 6$ & $\mathrm{R}$ & - & 一. \\
\hline
\end{tabular}

$\mathrm{N}$ denotes monoclinic needles $\left(\mathrm{CHPh}_{3}\right)$.

$R$ " rhombs $\left(\mathrm{CHPh}_{3} \cdot \mathrm{C}_{4} \mathrm{H}_{4} \mathrm{NH}\right)$.

In this case the range of existence of the compound is still further restricted, its solubility curve being cut by that for the pure substance at about $33^{\circ}$. The break in the curve is very slight, but a determination at $31^{\circ}$ showed that rhombs were on the more stable form at that temperature, since needles of the pure substance dissolved while the rhombs grew, whilst at $36^{\circ}$ the converse took place, showing that the needle-shaped crystals of the pure substance were the more stable form.

In this case, the different exten's of the "metastable region" for the two kinds of crystals is very well marked, for so soon as the limit for the more readily-formed rhombohedra is reached the curve falls almost vertically for a distance corresponding to $15^{\circ}$. In the crystallisations along this part of the curve, rhombohedra appear first in every case, and these serve as nuclei for the regular growth of crystals of pure triphenylmethane.

\section{The Compound of Triphenylmethane and Pyrrole.}

This substance had not been noticed previously, so two determinations of its composition were made by heating a known weight to $100^{\circ}$, with the following results :

0.1861 gram of the crystals lost 0.0388 gram on heating, corresponding to 20.86 per cent. pyrrole. 
TRIPHENYLMETHANE IN ORGANIC LIQUIDS.

0.1762 gram of the crystals lost 0.0349 gram on heating, corresponding to 19 per cent. pyrrole.

$\mathrm{CHPh}_{3} \cdot \mathrm{C}_{4} \mathrm{H}_{4} \mathrm{NH}$ requires a loss of $21 \cdot 29$ per cent.

FIa. 11.-Solubility and supersolubility curves of triphenylmethane in pyrrole.

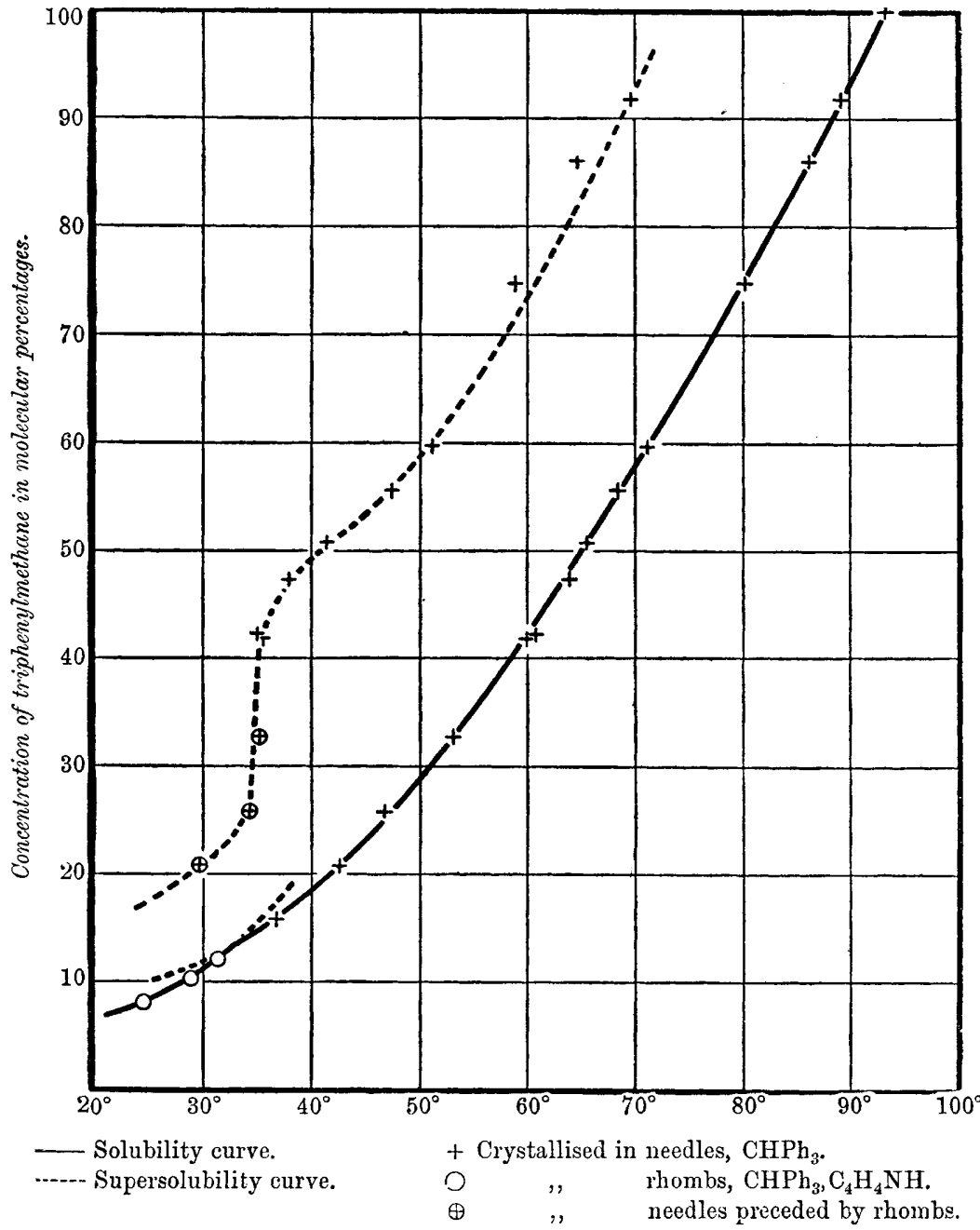

Hence the composition is similar to that of the benzene and thiophen compounds. The crystals lose pyrrole rapidly in the air, so that the low results are easily understood. The crystals show all the same properties as those of the two former compounds, and seem to 
be isomorphous with them. The tendency towards twinning is even greater in this case, and twinned crystals usually predominate over the simple rhomb. The fact that the rhombs can start the deposition of orthorhombic needles of triphenylmethane which grow on them, so that the vertical axes of both crystals are parallel, was first noticed with the pyrrole compound, as owing to the small region of stability of the rhombs it occurs much more often than with the other compounds.

\section{Triphenylmethane and Aniline.}

\section{Solubility of Triphenylmethane in Aniline.}

\begin{tabular}{|c|c|c|c|c|c|c|c|}
\hline $\begin{array}{l}\text { Gram of } \\
\text { triphenyl- } \\
\text { methane. }\end{array}$ & $\begin{array}{l}\text { Gram } \\
\text { of } \\
\text { aniline. }\end{array}$ & $\begin{array}{l}\text { Percent- } \\
\text { age of } \\
\text { triphenyl- } \\
\text { methane. }\end{array}$ & $\begin{array}{l}\text { Molecular } \\
\text { percent- } \\
\text { age of } \mathrm{S} \\
\text { triphenyl- } \\
\text { methane. }\end{array}$ & $\begin{array}{l}\text { Saturation } \\
\text { tem- } \\
\text { perature. }\end{array}$ & $\begin{array}{l}\text { Form } \\
\text { of } \\
\text { crystals. }\end{array}$ & $\begin{array}{l}\text { Limit of } \\
\text { metastable } \\
\text { region. }\end{array}$ & $\begin{array}{l}\text { Form } \\
\text { of } \\
\text { crystals. }\end{array}$ \\
\hline 0.5157 & 0.0211 & $96 \cdot 1$ & $90 \cdot 2$ & $87 \cdot 3^{\circ}$ & $\mathrm{N}$ & $69 \cdot 1^{\circ}, 68 \cdot 7^{\circ}$ & - N \\
\hline 0.5024 & 0.0452 & $91 \cdot 7$ & $80 \cdot 9$ & $82 \cdot 1$ & $\mathrm{~N}$ & $65 \cdot 6,64 \cdot 2$ & $\mathrm{~N}$ \\
\hline 0.5285 & 0.0942 & $84 \cdot 9$ & $68 \cdot 2$ & $74 \cdot 3$ & $\mathrm{~N}$ & $61 \cdot 1,59 \cdot 3$ & $\mathrm{RN}$ \\
\hline 0.4886 & $0 \cdot 1067$ & $82 \cdot 1$ & $63 \cdot \overline{5}$ & $71 \cdot 6$ & $\mathrm{~N}$ & $60 \cdot 7,60 \cdot 4$ & $\mathrm{RN}$ \\
\hline $0 \cdot 4869$ & $0 \cdot 1348$ & $78 \cdot 3$ & $57 \cdot 9$ & $70 \cdot 6$ & $\mathrm{R}$ & $62 \cdot 4,62 \cdot 2$ & $\mathrm{R}$ \\
\hline $0 \cdot 3750$ & $0 \cdot 1166$ & $76 \cdot 3$ & $55 \cdot 1$ & $71 \cdot 2$ & $\mathrm{R}$ & $62 \cdot 6,62 \cdot 4$ & $\mathrm{R}$ \\
\hline 0.3664 & $0 \cdot 1446$ & $71 \cdot 7$ & $49 \cdot 1$ & $71 \cdot 6$ & $\mathrm{R}$ & $62 \cdot 4,62 \cdot 2$ & $\mathrm{R}$ \\
\hline 0.3327 & 0.1572 & $67 \cdot 9$ & $44 \cdot 6$ & $71 \cdot 3$ & $\mathrm{R}$ & $63 \cdot 6,63 \cdot 1$ & $\mathrm{R}$ \\
\hline 0.2473 & 0.1358 & $64 \cdot 6$ & $40 \cdot 9$ & $70 \cdot 1$ & $\mathrm{R}$ & $62 \cdot 4,61 \cdot 2$ & $\mathrm{R}$ \\
\hline $0 \cdot 6066$ & 0.5011 & $54 \cdot 8$ & $31 \cdot 6$ & $68 \cdot 7$ & $\mathrm{R}$ & $61 \cdot 4,61 \cdot 1$ & $R$ \\
\hline 0.2020 & 0.2258 & $47 \cdot 2$ & $25 \cdot 4$ & $66 \cdot 0$ & $\mathrm{R}$ & $59 \cdot 8,59 \cdot 0$ & $\mathrm{R}$ \\
\hline $0 \cdot 2100$ & 0.3651 & $36 \cdot 5$ & $17 \cdot 8$ & $61 \cdot 4$ & $\mathrm{R}$ & $55 \cdot 2,53 \cdot 7$ & $\mathrm{R}$ \\
\hline $0 \cdot 1590$ & 0.5665 & $21 \cdot 9$ & $9 \cdot 7$ & $52 \cdot 1$ & $\mathrm{R}$ & $45 \cdot 2,44 \cdot 9$ & $\mathrm{R}$ \\
\hline $0 \cdot 1465$ & 0.9404 & $13 \cdot 5$ & $5 \cdot 6$ & $43 \cdot 0$ & $\mathrm{R}$ & $35 \cdot 5,35 \cdot 0$ & $\mathrm{R}$ \\
\hline 0.0451 & 0.4312 & $9 \cdot 5$ & $3 \cdot 8$ & $35 \cdot 3$ & $\mathrm{R}$ & - & - \\
\hline 0.0463 & 0.8061 & $5 \cdot 4$ & 1.85 & 23.0 & $\mathrm{R}$ & $\ldots$ & - \\
\hline
\end{tabular}

The solubility and supersolubility curves are very similar to those for benzene; the shape of the former curve indicates that the crystalline compound with the solvent, as in the case of benzene, is almost entirely dissociated in the solution.

\section{The Compound of Triphenylmethane and Aniline.}

The composition of this body was determined by weighing out a small quantity into a small flask with a rubber cork, through which passed a small tap funnel, a tube from a carbon dioxide apparatus, and another tube leading to a nitrometer filled with strong potash. Some dilute sulphuric acid was placed in the flask, and then all the air was driven out by a current of carbon dioxide; a small excess of potassium nitrite solution was then added through the tap funnel and the temperature of the flask raised slowly to $100^{\circ}$, when the liquid in it was boiled for ten minutes. All the evolved gases were then driven 
into the nitrometer by means of a current of carbon dioxide. Any traces of nitric oxide were oxidised by adding a little oxygen, the excess being absorbed with pyrogallate.

0.5856 gave 43.6 c.c. nitrogen at $19^{\circ}$ and $759 \cdot 3 \mathrm{~mm}$. $\mathrm{N}=4.38$.
0.6926 , $47 \cdot 7$ c.c.,$\quad 20^{\circ}$ and $756 \mathrm{~mm} . \quad \mathrm{N}=4.06$. $\mathrm{CHPh} h_{3} \cdot \mathrm{C}_{6} \mathrm{H}_{5} \mathrm{NH}_{2}$ requires $\mathrm{N}=4 \cdot 19$ per cent.

Fra. 12. - Solubility and supersolubility curves of triphenylmethane in aniline.

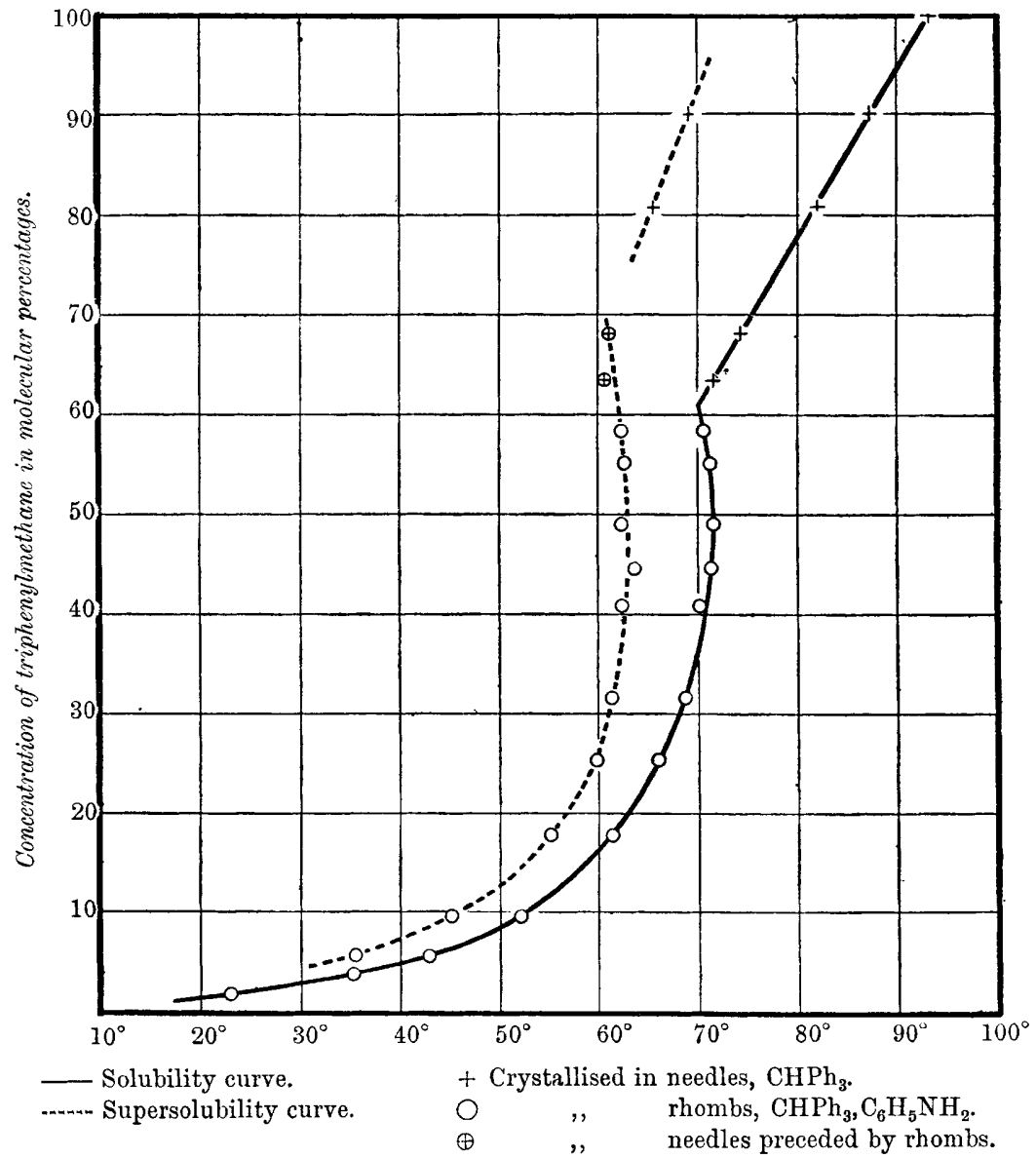

The substance is thus composed of molecular proportions of the two constituents as in the three previous cases; in crystalline form and habit, in twin formation, the property of causing the regular growth of orthorhombic crystals of triphenylmethane, and in optical properties,

VOL. I.XXXIX. 
it is practically identical with them. No evidence was found for the existence of the two modifications described by Lehmann, and it is quite clear from Lehmann's drawings that these two supposed forms are, as Hintze suggested, different habits of the same crystals.

Triphenylmethane and Pyridine.

Solubility of Triphenylmethane in Pyridine.

\begin{tabular}{|c|c|c|c|c|c|c|c|}
\hline $\begin{array}{l}\text { Gram of } \\
\text { triphenyl- } \\
\text { methane. }\end{array}$ & $\begin{array}{c}\text { Gram } \\
\text { of } \\
\text { pyridine. }\end{array}$ & $\begin{array}{l}\text { Percent- } \\
\text { age of } \\
\text { triphenyl- } \\
\text { methane. }\end{array}$ & $\begin{array}{l}\text { Molecular } \\
\text { percent- } \\
\text { age of } \\
\text { triphenyl- } \\
\text { methane. }\end{array}$ & $\begin{array}{l}\text { Saturation } \\
\text { tem- } \\
\text { perature. }\end{array}$ & $\begin{array}{c}\text { Form } \\
\text { of } \\
\text { crystals. }\end{array}$ & $\begin{array}{l}\text { Limit of } \\
\text { metastable } \\
\text { region. }\end{array}$ & $\begin{array}{c}\text { Form } \\
\text { of } \\
\text { crystals. }\end{array}$ \\
\hline 0.6799 & 0.0300 & $95 \cdot 8$ & $88 \cdot 1$ & $868^{\circ}$ & $\mathrm{N}$ & - & - \\
\hline 0.5907 & 0.0550 & $91 \cdot 5$ & $77 \cdot 2$ & $80 \cdot 6$ & $\mathrm{~N}$ & - & - \\
\hline 0.5480 & 0.0915 & $85 \cdot 7$ & $66 \cdot 4$ & $72 \cdot 8$ & $\mathrm{~N}$ & - & - \\
\hline 0.4610 & $0 \cdot 1017$ & $81 \cdot 9$ & $59 \cdot 7$ & $67 \cdot 8$ & $\mathrm{~N}$ & $46 \cdot 5^{\circ}, 44^{\circ} 7^{\circ}$ & $\mathrm{N}$ \\
\hline $0 \cdot 5132$ & $0 \cdot 1656$ & $75 \cdot 6$ & $50 \cdot 3$ & $59 \cdot 3$ & $\mathrm{~N}$ & $38 \cdot 1,37 \cdot 7$ & $\mathrm{~N}$ \\
\hline 0.5014 & 0.2138 & $70 \cdot 1$ & $43 \cdot 5$ & $53 \cdot 1$ & $N$ & $28 \cdot 9,28 \cdot 9$ & $\mathbf{N}$ \\
\hline 0.4457 & 0.2237 & $66 \cdot 6$ & $39 \cdot 5$ & $48 \cdot 7$ & $\mathrm{~N}$ & $24 \cdot 1,24 \cdot 0$ & $\mathbf{N}$ \\
\hline 0.3800 & 0.2800 & $57 \cdot 0^{3}$ & $30 \cdot 7$ & $37 \cdot 9$ & $\mathrm{~N}$ & - & - \\
\hline 0.3332 & 0.2918 & $53 \cdot 3$ & $27 \cdot 2$ & $31 \cdot 7$ & $\mathrm{~N}$ & - & - \\
\hline 0.2139 & $0 \cdot 2486$ & $46 \cdot 2$ & $22 \cdot 0$ & $22 \cdot 8$ & $N$ & - & 一 \\
\hline
\end{tabular}

In this case no compound is formed, and the solubility curve shows no break. Only a few determinations of the limit of the "metastable region" could be made, as at temperatures above $70^{\circ}$ the contents of the tubes became yellow owing to the presence of some decomposition product which seemed to disturb the normal course of crystallisation, for on cooling crystals did not, as in the other tubes, appear in the body of the liquid, but at some point on the glass.

\section{The Spontaneous Crystallisation of Supersaturated Solutions.}

Ostwald's classification of supersaturated solutions as "metastable" and "labile," according as they have or have not the property of spontaneous crystallisation, has been criticised by de Coppet (Bull. Soc. chim., 1901, 25, 388), who contends that there is no real distinction between the two classes. Arguing from a molecular theory of solution, de Coppet points out that crystallisation is produced by some particular concurrence of the solute molecules, which must happen sooner or later in any supersaturated solution, however small may be the degree of supersaturation. The probability that crystallisation will take place within a given time is obviously greater in a more concentrated solution, and de Coppet attributes the apparent difference between metastable and labile solutions to the different time required for crystallisation in the two cases. He has studied (Bull. Soc. chim., $1872,17,146$, and loc. cit.) the crystallisation of sodium sulphate by allowing sealed tubes containing a solution to cool until they were 
supersaturated and deposited crystals, but his experiments were not made over a sufficient range of concentration or under sufficiently definite conditions to give him a decisive result. They distinctly indicate, however, the existence of a "metastable limit," as crystals of $\mathrm{Na}_{2} \mathrm{SO}_{4}, 7 \mathrm{H}_{2} \mathrm{O}$ never appeared in the solution until $12^{\circ}$ below the saturation temperature. De Coppet does not admit that his results bear this interpretation, as in many instances tubes with the same

FIG. 13.-Solnubility and supersolubility curves of triphenylmethane in pyridine.

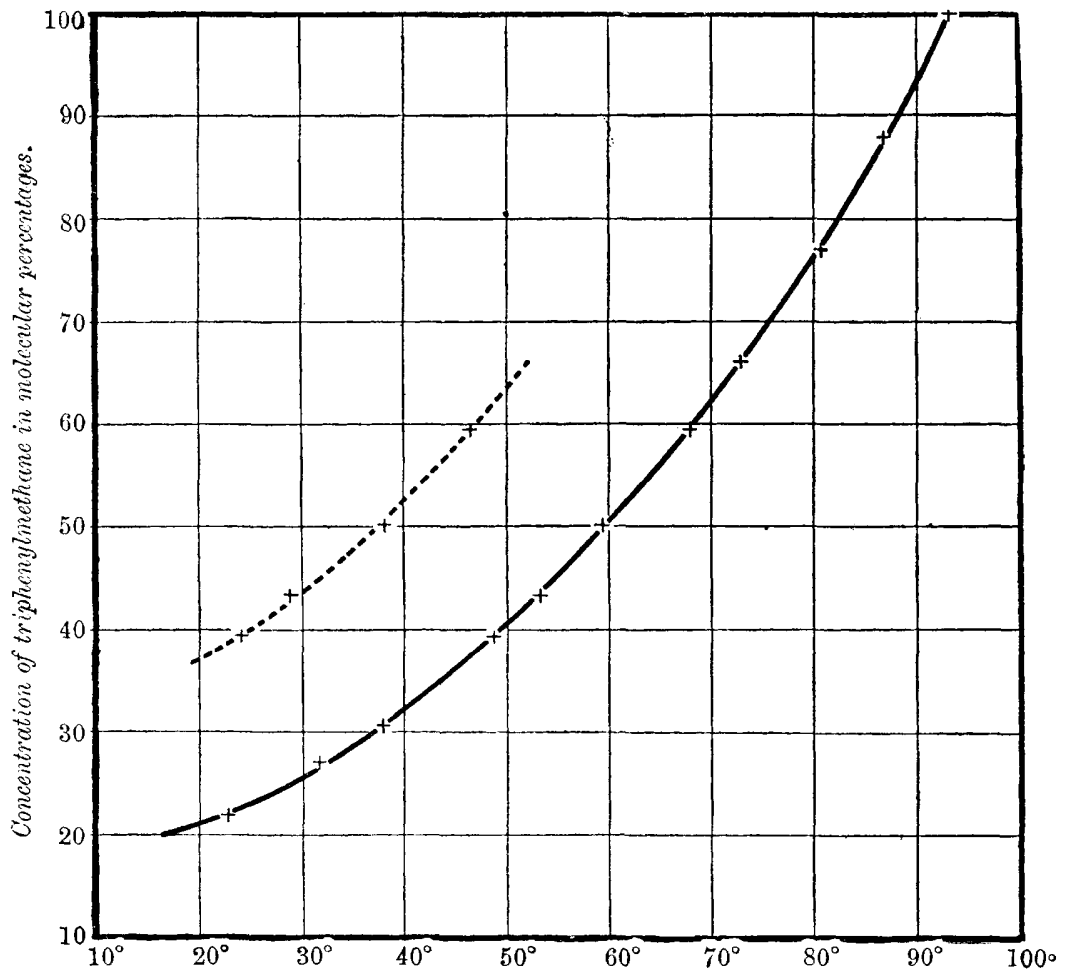

- Solubility eurve.

-...-. Supersolubility curve.

concentration crystallised at different temperatures, and the same tube in successive experiments gave very different results. This is not surprising, since de Coppet allowed his tubes to cool without shaking, and in a solution that is left undisturbed crystallisation may be deferred to an irregular, and at present unexplained, extent; vigorous shaking seems to be the surest way to make a solution crystallise as soon as it is capable of doing so. 
The experiments of Miers and Miss Isaacs (Trans., 1906, 89, 413) and those described in the present paper definitely prove the existence of a "metastable limit" in the case of solutions both in water and organic liquids. It is represented by the supersolubility curve, which gives the temperature at which solutions of different concentration crystallise spontaneously when cooled with constant shaking, that is, the temperature at which they pass from the metastable to the labile condition. This curve is always found to run approximately parallel to the solubility curve, at a distance from it depending on the respective solute and solvent. No instance was found in the large number of experiments made to determine these curves in which a solution freed from crystalline nuclei by previous heating crystallised when in the metastable region: so that it would seem that the difference between the two kinds of solutions is something more than one of degree.

Ostwald is inclined to be sceptical of kinetic theories of solution and crystallisation, and looks to the phenomena of surface energy for an explanation of these questions. The kinetic theory of crystallisation has, however, so many advantages as a guide in experimeutal work that it is as well to see if it cannot throw some light on the facts observed. Ostwald's criticism of it is based mainly on some observations of de Boisbaudran and of Gernez on the "inertia" of crystal faces towards small changes of concentration, and on some observations respecting the effect of crystals on supersaturated solutions of salts isomorphous with them. It must be noticed that all these were merely qualitative observations which have not received quantitative proof. In the solubility method used by the authors in the present paper, no trace of this inertia was perceptible; on the other hand, very small changes of temperature produced immediate effects on the apperance of the faces of the crystal when the solutions were well stirred, a condition which is not mentioned by either of the above authors.

If we consider crystallisation and solution from the kinetic standpoint, we must suppose that a solvent has the power to carry off molecules from the surface of a crystal by some chemico-physical action, the exact nature of which is not yet known. This action is opposed by the attractive force exerted by the molecules in the crystal on one another, and on any solute molecules which approach the crystal from the solution: so that it is the combined effret of these two forces preducing erosion and accretion which conditions crystalline growth. The attractive force acting on a particular molecule must be due to a limited number of molecules in its immediate neighbourhood. When crystals are large compared with molecular distances, this force will assume its maximum value at all points 
on a crystal face except near the edges, where, as Willard Gibbs has pointed out, the force protecting the molecules of the crystal from erosion will be smaller than at the centre. As the size of a crystal is diminished, the variation of this molecular force will gradually become more perceptible, as every point on a crystal face comes nearer and nearer to an edge. Decrease in size will therefore be accompanied by an increase in solubility. This question has been studied by J. J. Thomson and others from a consideration of the surface energy of a crystal; their conclusions as to the relation of solubility to size have been verified by Ostwald (Zeit. physikal. Chem., 1900, 34, 495) and by Hulett (Zeit. physikal. Chem., 1901, 37, $385)$.

Why then should a supersaturated solution exist without crystallis ag? On the kinetic theory of solution, molecules of the solute n.ast constantly collide with and exert attractive forces on one another, so that there seems to be no reason why some small number of molecules should not meet and form a nucleus for crystallisation by the gradual accretion of other molerules. The explanation why this does not lead to crystallisation in the metastable region probably lies in the variation of molecular forces in the early stages through which a crystal formed in this way has to pass. A solution which is but slightly supersaturated for microscopic crystals would be unsaturated for the very small crystal individuals which must be the first products in a spontaneous crystallisation. It is therefore probable that these would be dispersed hefore they could pass through the critical stages of their early growth; for it must be remembered that in these stages not only is the erosive action of the solvent more powerful, but also the attractive force of the cry-tals on solute molecules is relatively smaller; thus the time necessary for growth and the probability that the crystal will be dispersed are both increased. Up to a certain limit of supersaturation it would not be surprising if it were impossible for a crystal to persist through these initial stages, but when the supersaturation became large enough to counteract the increased solubility of the incipient crystal, spontaneous crystallisation would take place within a longer or shorter period, depending on certain physical conditions. Supposing these to be favourable, as seems to be the case when the solution is vigorously shaken or stirred, we might expect crystallisation to start at a number of different points in the liquid and to proceed rapidly, exactly as was observed in the experiments previously described. During the initial stages of growth, the solution, although it is giving up dissolved matter to the crystals, is also quickly becoming more supersaturated with respect to them, hence, at the start, the rate of growth should be very rapid; this agrees with the observations of Richards and Archibald (Proc. Amer. 
Acad., 1901, 36, 341), who photographed the various stages of development of a crystal.

It is thus possible to explain from a kinetic standpoint why supersaturation is so general a phenomenon and why there should be a metastable limit dividing solutions which will crystallise spontaneously from those which will not.

The production of crystals in a metastable solution differs from the formation of liquid drops in a metastable supersaturated vapour, as in the latter case any foreign body, for example, a dust particle, or the walls of the containing vessel, is able to produce condensation, while in the former only a body with an identical or closely related crystal structure can start crystallisation. In some of the experiments made to determine the supersolubility described in the present paper, particles of foreign matter were visible in the tubes, but these did not bring about crystallisation, which occurred regularly throughout the liquid and did not start from the solid impurities present.

Thus, in a metastable solution, the presence of a surface exerting definitely orientated molecular forces is necessary to give rise to a definite crystal structure.

Since writing the above, the authors have found that a somewhat similar explanation of the nature of metastable and labile solutions has already been given by Küster (Zeit. anorg. Chem., 1903, 33, $363)$.

\section{Summary.}

(1) Kuriloff's method for determining solubilities has been slightly modified, and has been found very useful when only small quantities of substance are available and the solvent is volatile. It also admits very easily of the determination of the limit of the "metastable region" of a solution, that is, the temperature at which crystals are spontaneously produced without the addition of crystalline nuclei.

(2) The solubility of triphenylmethane in benzene, thiophen, pyrrole, aniline, and pyridine has been determined; the results for benzene agree with those of Kuriloff.

(3) Triphenylmethane crystallises in certain circumstances from solutions in benzene, thiophen, pyrrole, and aniline with one molecule of the solvent combined in a manner similar to that of "water of crystallisation."

(4) Microscopic examination of the four compounds has shown that they have almost identical crystalline forms with the same habit, twin law, and optical properties, so that they probably form an isomorphous series.

(5) Rhombohedral crystals of each of these compounds have the property of causing the growth of orthorhombic crystals of triphenyl- 
LOWRY: STUDIES OF DYNAMIC ISOMERISM. PART IV. $1033^{\text {View Article }}$

methane when placed in solutions which are metastable as regards the latter body. This is additional evidence in favour of their isomorphism.

(6) The "supersolubility curve," that is, the limit of the " metastable region," has been determined in each case. For all five solvents the curve runs approximately parallel to the solubility curve, being about $20^{\circ}$ distant from it for the crystallisation of pure triphenylmethane, and about $7^{\circ}$ distant for the crystallisation of the compounds containing a molecule of solvent.

The authors wish to express their indebtedness to Mr. B. M. Jones, late Scholar of Balliol College, for his valuable assistance in a number of the determinations, and to Mr. D. H. Nagel, Trinity College, Oxford, for the interest he has taken in the progress of their work.

Balliol and Trinity College laboratory, OXFORD. 